\title{
Mahsa Veisi, Alireza Hejebri Nobari, Seyed Mousavi Koohpar, Javad Neyestani. « An Inverstigation of the Geometric Proportions of Bell-Shaped Column Bases and Bull Capitals at Persepolis and in Caucasian Achaemenid Sites »
}

\section{Rémy Boucharlat}

\section{OpenEdition}

\section{Édition électronique}

URL : http://journals.openedition.org/abstractairanica/45727

DOI : 10.4000/abstractairanica.45727

ISBN : 1961-960X

ISSN : 1961-960X

Éditeur :

CNRS (UMR 7528 Mondes iraniens et indiens), Éditions de l'IFRI

\section{Référence électronique}

Rémy Boucharlat, « Mahsa Veisi, Alireza Hejebri Nobari, Seyed Mousavi Koohpar, Javad Neyestani. "An Inverstigation of the Geometric Proportions of Bell-Shaped Column Bases and Bull Capitals at Persepolis and in Caucasian Achaemenid Sites » », Abstracta Iranica [En ligne], Volume 37-38-39 | 2018, document 65, mis en ligne le 30 décembre 2018, consulté le 27 septembre 2020. URL : http:// journals.openedition.org/abstractairanica/45727 ; DOI : https://doi.org/10.4000/abstractairanica. 45727

Ce document a été généré automatiquement le 27 septembre 2020.

Tous droits réservés 


\title{
Mahsa Veisi, Alireza Hejebri Nobari, Seyed Mousavi Koohpar, Javad Neyestani. « An Inverstigation of the Geometric Proportions of Bell- Shaped Column Bases and Bull Capitals at Persepolis and in Caucasian Achaemenid Sites »
}

\author{
Rémy Boucharlat
}

\section{RÉFÉRENCE}

Mahsa Veisi, Alireza Hejebri Nobari, Seyed Mousavi Koohpar, Javad Neyestani, « An Inverstigation of the Geometric Proportions of Bell-Shaped Column Bases and Bull Capitals at Persepolis and in Caucasian Achaemenid Sites ", Ancient Civilizations from Scythia to Siberia, 20/2, 2014, p. 195-211

À partir des découvertes, maintenant nombreuses, de bases de colonne en pierre campaniformes sur plusieurs sites des républiques du Caucase (Géorgie, Arménie, Azerbaijan), les A montrent que les architectes de ces monuments ont tenté de reproduire forme et proportions des bases de Persépolis. Ils notent cependant des différences qu'ils attribuent au travail local. En réalité, on observe aussi de légères différences de proportions à Persépolis même, parfois de Persépolis à Suse ou à Qaleh Kali (Fahlian, Mamassani). Les AA. soulignent avec raison qu'il n'y a pas de traditions d'architecture de pierre taillée avant l'époque achéménide dans le Caucase. Est-ce pour eux une explication aux différences, du fait d'artisans - locaux peu expérimentés, dans 
l'idée des AA. ? - Il faut alors rappeler qu'il n'y avait pas non plus de tradition en Iran avant les Achéménides, que ce soit dans la région de Persépolis, celle de Suse ou encore celle d'Ecbatane. À partir de ces documents, il vaudrait mieux souligner la création de modèles d'architecture et de décor relevant l'art achéménide dans l'ensemble de l'empire, ou du moins dans plusieurs régions, plutôt qu'une simple diffusion unidirectionnelle du centre vers la périphérie.

\section{AUTEURS}

RÉMY BOUCHARLAT

UMR 5133 CNRS-Université de Lyon 